\title{
Crohn's Disease and Stroke in a Young Adult
}

\author{
Emina Ogawa ${ }^{1}$, Ryuji Sakakibara ${ }^{1}$, Yasushi Yoshimatsu ${ }^{2}$, Yasuo Suzuki ${ }^{2}$, Takayuki Mouri ${ }^{3}$, \\ Fuyuki Tateno ${ }^{1}$, Masahiko Kishi ${ }^{1}$, Shunsuke Oda ${ }^{1}$ and Haruki Imamura ${ }^{1}$
}

\begin{abstract}
A 36-year-old man with a 21-year history of Crohn's disease suddenly developed left hemiparesis. He did not have atherosclerotic risk factors on admission, but he had marked dehydration which was likely due to prolonged home intravenous hyper-alimentation. Brain MRI revealed lacunar infarction in the right anterior corona radiata. An anticoagulation drug and a free-oxide scavenger successfully reversed his neurological deficits almost completely. Stroke in young adults less than 40 years old is extremely rare; therefore, we conclude that Crohn's disease can be a risk factor for acute ischemic stroke in our case, due most probably to dehydration and other complex mechanisms.
\end{abstract}

Key words: Crohn's disease, stroke, young adult

(Intern Med 50: 2407-2408, 2011)

(DOI: 10.2169/internalmedicine.50.5692)

\section{Introduction}

Stroke in children and young adults (less than 40 years old) is extremely rare, the incidence being estimated as only $2.2 \%$ of all stroke cases (1). It has recently been recognized that stroke in those patients can be triggered by Crohn's disease (2), an inflammatory bowel disease that preferentially affects children and young adults. Here, we present a man with Crohn's disease who developed acute ischemic stroke.

\section{Case Report}

A 36-year-old man had a 21-year history of Crohn's disease, which had been diagnosed and followed by a local hospital because of abdominal pain, bloody diarrhea, and abnormalities in gastrointestinal endoscopy and imaging. $\mathrm{He}$ had a longitudinal ulcer from mid to distal ileum and ileoileal stoma. He had been treated with mesalazine and azathiopurine. However, he underwent colonic semi-total resection, ileal resection, and the surgical procedure for ileostomy at age 22. Pathology specimens showed multiple fissuring ulcer, whole-layer inflammation and non-cascading epithelioid cell granuloma. Because of short bowel syndrome, he started at that time to use home parenteral nutri- tion. The constituents of home parenteral nutrition 'Fullcalic No. 3' included 2,206 mL water, 2,320 Cal, glucose $500 \mathrm{~g}$, sodium $100 \mathrm{mEq}$, potassium $60 \mathrm{mEq}$, amino acid $80 \mathrm{~g}$, etc. One year before arrival, laboratory test results were as follows: total protein $8.9 \mathrm{mg} / \mathrm{dL}$, albumin $4.2 \mathrm{mg} / \mathrm{dL}$, blood urea nitrogen $14 \mathrm{mg} / \mathrm{dL}$, creatinine $1.08 \mathrm{mg} / \mathrm{dL}$, no blood sugar data, and hemoglobin $14.9 \mathrm{~g} / \mathrm{dL}$.

In the morning for the first time, he suddenly developed left hemiparesis, which is why he presented at our university hospital. On admission, the patient's blood pressure was $120 / 80 \mathrm{~mm} \mathrm{Hg}$. He was experiencing mild disorientation, and was revealed to have mild paretic dysarthria, left hemiparesis, and extensor plantar reflex in the left side. Sensation was normal. Laboratory examination revealed an increase in total protein $(9.7 \mathrm{mg} / \mathrm{dL})$, blood urea nitrogen $(22.4 \mathrm{mg} / \mathrm{dL})$, blood sugar $(117 \mathrm{mg} / \mathrm{dL})$, hemoglobin $(18.0 \mathrm{~g} / \mathrm{dL})$, plasma osmolality $(296.1 \mathrm{mOsm} / \mathrm{L})$, all indicating dehydration due probably to water loss from the ileal stoma and the prolonged use of home IVH. Coagulation test results were normal. Electrocardiography, echo cardiography, and carotid echography showed normal findings. Brain MRI showed a lacunar infarction in the right corona radiata (Fig. 1). He was started on $1,500 \mathrm{ml} /$ day saline, $160 \mathrm{mg} / \mathrm{day}$ intravenous ozagrel and $60 \mathrm{mg} /$ day edaravone for 14 days. These treatments successfully ameliorated his neurological deficits.

${ }^{1}$ Neurology, Internal Medicine, Sakura Medical Center, Toho University, Japan, ${ }^{2}$ Gastroenterology, Internal Medicine, Sakura Medical Center, Toho University, Japan and ${ }^{3}$ Information Technology System, Sakura Medical Center, Toho University, Japan

Received for publication April 23, 2011; Accepted for publication July 5, 2011

Correspondence to Dr. Ryuji Sakakibara, sakakibara@sakura.med.toho-u.ac.jp 


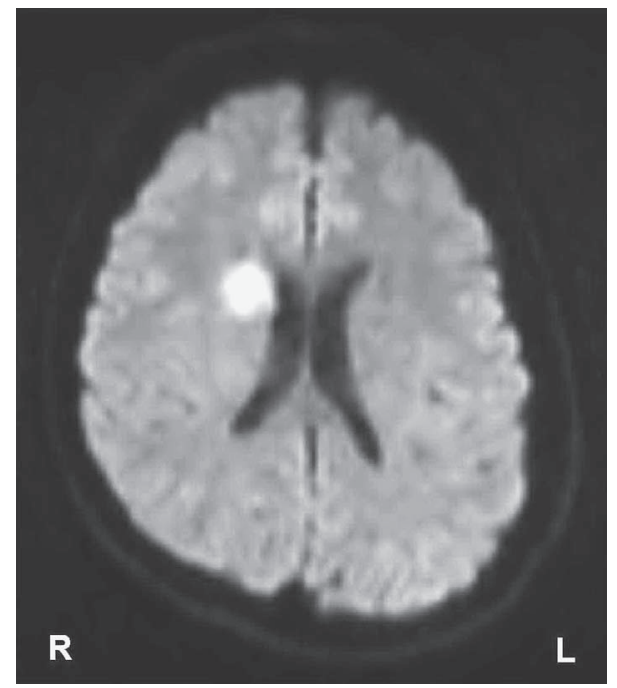

Figure 1. MRI of the patient. The brain MRI taken on admission using diffusion-weighted images showed a small highsignal lesion in the right anterior corona radiata that corresponded to an infarction in the right striatocapsular artery area.

Laboratory abnormalities returned to normal at that time. $\mathrm{He}$ was started on $75 \mathrm{mg} / \mathrm{day}$ clopidogrel sulfate. The constituents of home parenteral nutrition were changed to 'Fullcalic No. 1', including 2,206 mL water, 1,806 Cal, glucose $240 \mathrm{~g}$, sodium $100 \mathrm{mEq}$, potassium $60 \mathrm{mEq}$, amino acid $40 \mathrm{~g}$, (less glucose and amino acid than Fullcalic No. 3) and he had no recurrence of stroke during the subsequent two years.

In the past 11 years in the gastroenterology in our hospital, the incidence of stroke among Crohn's disease patients with age $<40$ years and those with age $>40$ years was one (the present case)/352 (0.3\%) and 2/113 (1.8\%), respectively.

\section{Discussion}

The incidence of stroke in young adult Crohn's disease patients in the present study was in accordance with those in the recent studies. Bernstein reported the incidence of stroke in children and young adults ( $<40$ years) Crohn's disease patients and controls as 12.5/10,000 (0.125\%) and 11.7/ $10,000(0.117 \%)$, respectively (3). Barclay reported two cases of stroke in children with Crohn's disease, and the incidence rate was 2/99 (2\%) per 5 years (4). A detailed link between Crohn's disease and stroke remains uncertain. Crohn's disease is characterized by an exaggerated immune response to the microbial flora inhabiting the lumen of the gut (2), involving endothelium, platelets, and leukocytes $(5,6)$. In agreement with these findings, recent case reports of stroke in Crohn's disease patients suggested active disease (4), hypercoagulation and dehydration $(7,8)$, and vasculitis (9) as contributory factors for developing stroke (10). In the present patient, blood hyper-concentration due to dehydration and other complex mechanisms most likely contributed to stroke.

Stroke in young adults less than 40 years old is extremely rare; therefore, we conclude that Crohn's disease may be a risk factor for the development of acute ischemic stroke in the present case, due most probably to dehydration and other complex mechanisms.

\section{The authors state that they have no Conflict of Interest (COI).}

\section{References}

1. Yasaka M, Minematsu K. Stroke in young adults in Japan. Rinsho Shinkeigaku 45: 842-845, 2005 (in Japanese).

2. Griffiths AM. Specificities of inflammatory bowel disease in childhood. Best Pract Res Clin Gastroenterol 18: 509-523, 2004.

3. Bernstein CN, Wajda A, Blanchard JF. The incidence of arterial thromboembolic diseases in inflammatory bowel disease: a population-based study. Clin Gastroenterol Hepatol 6: 41-45, 2008.

4. Barclay AR, Keightley JM, Horrocks I, Garrick V, McGrogan P, Russell RK. Cerebral thromboembolic events in pediatric patients with inflammatory bowel disease. Inflamm Bowel Dis 16: 677683, 2010.

5. Scaldaferri F, Sans M, Vetrano S, et al. Crucial role of the protein $\mathrm{C}$ pathway in governing microvascular inflammation in inflammatory bowel disease. J Clin Invest 117: 1951-1960, 2007.

6. Matsumoto T, Iida M, Motoya $S$, et al. Therapeutic efficacy of infliximab on patients with short duration of Crohn's disease: a Japanese multicenter survey. Dis Colon Rectum 51: 916-923, 2008.

7. Calderón R, Cruz-Correa MR, Torres EA. Cerebral thrombosis associated with active Crohn's disease. P R Health Sci J 17: 293295, 1998.

8. Standridge S, de los Reyes E. Inflammatory bowel disease and cerebrovascular arterial and venous thromboembolic events in 4 pediatric patients: a case series and review of the literature. J Child Neurol 23: 59-66, 2008.

9. Schluter A, Krasnianski M, Krivokuca M, Spielmann RP, Neudecker S, Hirsch W. Magnetic resonance angiography in a patient with Crohn's disease associated cerebral vasculitis. Clin Neurol Neurosurg 106: 110-113, 2004.

10. Andersohn F, Waring M, Garbe E. Risk of ischemic stroke in patients with Crohn's disease: a population-based nested case-control study. Inflamm Bowel Dis 16: 1387-1392, 2010.

(C) 2011 The Japanese Society of Internal Medicine

http://www.naika.or.jp/imindex.html 